\title{
Semblanza
}

\section{Carlos Alberto Seguín: Paradigma docente de la Facultad de Medicina de San Fernando, a 100 años de su nacimiento *}

\author{
Carlos Alberto Seguin: San Fernando School of Medicine's teacher paradigm, \\ 100 years from his birth
}

\author{
Alberto Perales ${ }^{1}$ \\ * Trabajo presentado en la Ceremonia realizada el 6 de agosto de 2007, con ocasión del Centenario del Nacimiento del Dr. Carlos Alberto Seguín, en la Facultad de \\ Medicina de San Fernando, evento organizado por el Departamento de Psiquiatría de la Facultad. \\ Profesor de Psiquiatría y Director del Instituto de Ética en Salud, Facultad de Medicina, Universidad Nacional Mayor de San Marcos. Lima, Perú.
}

\begin{abstract}
Resumen
A propósito del primer centenario del nacimiento (1907-2007), de Carlos Alberto Seguín, describimos tres facetas de su ejemplar trayectoria: sus años formativos, su presencia en la Facultad de Medicina de San Fernando, en el difícil periodo de los 60, y su digna actitud ante la muerte. Las avanzadas ideas sobre la nueva formación médica que Seguín postulaba, insistiendo en la necesidad de estudiar, diagnosticar y tratar tanto el área psicológica cuanto física del ser humano y no solo 'su enfermedad'. Además, su propuesta metodológica de los 'grupos formativos', para que los estudiantes tuvieran la oportunidad de elaborar sus vivencias de contacto con el enfermo, no fueron bien comprendidas en la época que las formulara, creándose conflictos que el profesor prefirió evitar por el bien de la institución y porque comprendió que el estudiante de esa época no estaba dispuesto a realizar el esfuerzo necesario para tal logro. Su digna actitud ante la muerte se grafica en un verso que escribiera poco antes de morir. Seguín falleció el sábado 26 de agosto de 1995. Debe ser recordado como un paradigma docente sanmarquino.

Palabras clave: Seguín, Carlos Alberto; educación médica; psiquiatría.
\end{abstract}

\begin{abstract}
Celebrating Carlos Alberto Seguin's first birth centenary (1907-2007) the author describes three facets of his exemplary life: his formative years, his presence in San Fernando School of Medicine during the difficult 60's and his dignified attitude facing death. The advanced Seguin's ideas upon medical education reform, joining the psyche and physical parts of human beings as an integral whole made him postulate to diagnose and treat not only 'the illness' but the whole person. Moreover, his methodological proposal of 'formative groups' in order to give the students the opportunity to elaborate their emotional reactions while interacting patients, were not well understood and caused conflicts that he preferred to avoid for the institution's sake. He sadly understood that students of that time were not willing to make the necessary efforts to reach their best academic goal. Finally, his dignified attitude in front of death is described in a poem he wrote just before dying. Seguin died on Saturday August 26, 1995. He should be remembered as a sanmarquino teaching paradigm.
\end{abstract}

Key words: Seguin, Carlos Alberto; education, medical; psychiatry.
Hablar de Seguín es hablar de gran parte de la psiquiatría peruana del siglo XX. No exageramos al afirmar que, por lo menos la mitad de los psiquiatras peruanos actuales y muchos otros profesionales de la salud, fueron influidos, directa o indirectamente, por su pensamiento y enseñanzas (Figura 1).

Para describir con propiedad su vasto quehacer y ampliando la expresión del biógrafo que más lo conoce, Max Silva Tuesta, tocaré tan solo algunas facetas de su trayectoria (1), organizando mi participación en torno a tres periodos de su ciclo vital: sus años formativos, su participación docente en San Fernando y su actitud ante la muerte.

\section{LOS AÑOS FORMATIVOS}

Carlos Alberto Seguín nació un jueves 8 de agosto de 1907, en la soleada ciudad de Arequipa. Hijo de un periodista y político, don Alberto Gonzalo Seguín, y de la dama arequipeña doña Emma Escobedo conoció, desde pequeño, la vital circulación de la noticia y de la prensa. Su padre, propietario y Director del Diario 'El Heraldo', realizaba su edición en la imprenta que tenía en su propia casa.

Pronto, el pequeño Carlos Alberto habría de comprender los sinsabores de la política. Su padre fue deportado, primero a Bolivia y después a la Argentina, por no coincidir en sus escritos periodísticos con el régimen de turno. Por esta razón, Carlos Alberto terminó sus estudios escolares y profesionales en el país del sur. Se graduó de médico el 4 de abril de 1932, en la Universidad de Buenos Aires. El año anterior había publicado ya su primer libro, un tratado de Farmacología, que posteriormente sería utilizado como texto en dicho centro de estudios. Luego de graduado, ejerció su práctica profesional lejos de la gran urbe y afincó en la Provincia de Formosa, en el norte de Argentina.

Dedicado a la medicina general, cirugía y obstetricia, un incidente marcaría su destino y lo orientaría hacia la psiquiatría. Un día recibió en consulta a un hombre, preocupado por molestias precordiales. Seguín, buen clínico y diagnosticador, lo examinó y no encontró signos de patología. Comunicó la noticia al enfermo e intentó tranquilizarlo, con sus hallazgos negativos. Poco después, el paciente retornó, aquejando iguales molestias. Seguín repitió los exámenes con iguales resultados y reiteró su diagnóstico y comentario "No tiene Ud. nada y no debe preocuparse", al despedirlo. Semanas más tarde, habrá de enterarse del suicidio del enfermo. Desde entonces, y por siempre, lamentaría su tardía comprensión de la esencia de la medicina "No tratar enfermedades sino enfermos". La 
experiencia lo marcaría indeleblemente. Si bien su perspectiva médica seguirá siendo holística, pondría gran énfasis en el valor de la relación emocional del acto médico y en el amor que el buen médico debe ofrecer a sus pacientes, amor que, expresando al mismo tiempo su vocación de servicio y compromiso humano, se convirtió en el estímulo madurativo fundamental para el logro terapéutico.

A esa medicina, Seguín la llamaría 'medicina de hombres', en clara alusión crítica a la práctica profesional deshumanizada y sesgada al estudio y tratamiento de "la enfermedad y del cuerpo enfermo y no del ser humano en situación de enfermedad". Seguín inició, así, su vinculación con la psiquiatría.

En 1939, decidió retornar a su país. Al año siguiente ingresó a trabajar al Hospital Obrero de Lima. En 1942, se graduó de Doctor en Medicina, con una brillante tesis sobre hipnotismo. Poco después, partió a Estados Unidos, para adiestrarse formalmente en psiquiatría en el Institute of Living, en Hartford, Connecticut. Finalizado su adiestramiento $y$, pese al ofrecimiento de un excelente puesto de trabajo, clínico y universitario, decidió retornar al Perú. Desde entonces, Seguín generó una febril actividad profesional.

\section{SEGUÍN EN LA DOCENCIA Y EN SAN FERNANDO}

Seguín fue hombre de vida intensa. Se le puede describir diciendo que "amó la vida y al ser humano, particularmente en situación de enfermedad". Su pasión era enseñar. Tenía una voracidad de aprendizaje, pero, también, una necesidad compulsiva de transmitirlo, como si en la tertulia intelectual con el alumno recién comprendiera y gozara el contenido del conocimiento adquirido. Para él, aprender era aprender con el otro y para el otro. En tal perspectiva, fue fundamentalmente un Maestro, porque maestro es, según Diego Gracia, "aquel que nunca coarta la originalidad propia, sino que más bien, la posibilita. Los grandes maestros se diferencian de los pequeños en que los primeros ayudan a pensar, a crear, y por tanto a ir más allá de ellos; en tanto que los segundos tienen que basar su ascendiente en criterios de autoridad..." (2).

José Alva ha descrito con particular acierto la faceta docente de Seguín, para quien enseñar "no solo era un saber y un quehacer sino, sobre todo, una íntima misión existencial de donación, solidaridad y realización personal...... Enseñaba que en el acto médico, al lado de la magia de la palabra, había que emplear el arte del escuchar empático" (3). A lo que Saúl Peña agregará: "que se escucha con el alma y se oye con los oídos, porque la psicoterapia es una actividad auditiva" (4).

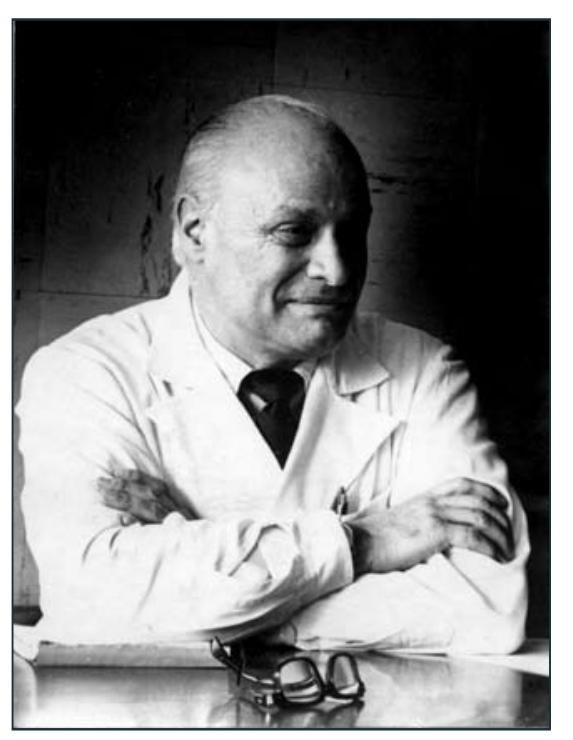

Figura 1. Carlos Alberto Seguin (1907-1995).

La prédica seguiniana, se sintetiza, según José Alva, en:

- "El buscar siempre el rostro humano en toda dolencia.

- El destacar los componentes sicológicos del acto médico.

- El considerar los factores biosicosociales en la génesis y en el tratamiento de las dolencias.

- El analizar el proceso psicodinámico de la conducta humana.

- El considerar la importancia de la medicina tradicional y la medicina folclórica” (3).

Al producirse la escisión sanfernandina, en 1961, con la renuncia de la mayoría de sus profesores, los cuales habrían de formar la nueva Facultad de Medicina Peruana Cayetano Heredia, Seguín es llamado a colaborar en la reestructuración de nuestra casa de estudios. No lo duda un instante, pero exige que su ingreso sea por concurso. Así ocurre, para luego participar en la selección de profesores, organizando el concurso correspondiente. A tal exigencia habrá de presentarse todo su equipo de colaboradores (Figura 2), Andrés Cáceres, uno de sus más dedicados discípulos, ha reseñado muy bien sus postulados docentes y motivación a participar en estos acontecimientos, argumentando que Seguín señalaba en ese entonces lo siguiente: "en la carrera médica, es necesaria una renovación total de la enseñanza, con una preparación humanista de amplia base en premédicas y que, después, a lo largo de toda la carrera, en forma paralela y en relación con los otros cursos, se enseñe también psicología médica (relación médico-paciente), anatomía y fisiología de las emociones, psicología dinámica, estructura de la personalidad, psicopatología, semiología psicosomática -aprendiendo a confeccionar una historia clínica biográfica completa- nosografía psiquiátrica y, finalmente, clínica psiquiátrica. De esa manera, no existe separación formal entre la enseñanza 'somática' y 'psicológica'; son diferentes aspectos del mismo tema. La terapéutica debe ser completada con un conocimiento adecuado de la psicoterapia para el médico práctico. Debe comprenderse, además, los componentes psicosociales del trastorno" ${ }^{(5)}$.

En suma, Seguín aspiraba a que el médico comprendiera al paciente como persona, poseedor de una biografía, a quien debía estudiar con todos los medios que le brinda la ciencia, pero añadiendo la dimensión humana para comprender sus problemas psicológicos, sociales y espirituales. Solo así, su magna tarea de médico sería no solo una profesión sino un apostolado ${ }^{(5)}$.

En 1962, con esas ideas en mente, reorganiza el Departamento de Psiquiatría, renombrándolo Departamento de Ciencias Psicológicas. Y elabora un ambicioso programa para cambiar la orientación de la docencia, tal como siempre lo había soñado, formar médicos que ejercieran la medicina con enfoque personal e integral, y atendieran seres humanos enfermos y no solo cuerpos descompuestos. Seguín tuvo, para tal finalidad, una visión clara de las dificultades académicas inmersas en modificación tan radical de la enseñanza; pero, lamentablemente, ignoraría las variables políticas de resistencia que suelen aparecer ante toda amenaza de cambio. Su creativa propuesta comenzó a implementarse en la Facultad de Medicina, desde 1962, pero se frustró poco después. Un núcleo de profesores, en concertación con un grupo de alumnos, socavaron el movimiento, cuando Seguín implementaba una brillante iniciativa, la organización de los Grupos Formativos, programa que intentaba ofrecer al estudiante un espacio de maduración, no solo intelectual sino emocional y espiritual, reflexionando sobre sí mismo en tanto que persona. Ante la oposición, que llegó a niveles inadecuados, Seguín renunció con una carta, en la que luego de exponer las razones de su decisión, dice en un párrafo final: "...no quiero seguir enseñando a alumnos que no quieren aprender...”. 


\section{SEGUÍN ANTE LA MUERTE}

Los adelantos tecnológicos de la medicina actual han variado el concepto de muerte, incluso su definición. Ya no basta, para certificarla, que un individuo deje de respirar y su corazón de latir. En tales circunstancias, reanimarlo es aún posible. Por otro lado, la medicina ha desarrollado nuevas posibilidades terapéuticas, lo cual permite superar situaciones críticas que antaño conducían inexorablemente al deceso. En términos simples, un paciente ya no puede morir cuando quiere ni cuando le corresponde; ahora, debe pedir permiso a los médicos y a los familiares para que lo dejen morir en paz. Lo importante de todo este final proceso, más allá de la forma o el estilo propio de morir de cada persona, es morir con dignidad.

Sobre el tema de su muerte, en ocasión anterior escribí lo siguiente:

"Y así murió Seguín (con dignidad). Ya en las últimas décadas de su existencia, un grupo de sus discípulos solía visitarlo dominicalmente y gozar de su sazonada experiencia. Seguín gustaba enfatizar su deseo de vivir hasta los 90; quería experimentar, decía, ¡Qué se siente a esa edad! Poco antes de morir, nos comunicó un secreto. En cada década de su existencia había escrito un poema, que expresaba su visión de la vida en tal momento. Fue un verdadero placer espiritual escuchar tales versos. El último, el de los 80 años, me impresionó por su fuerza, su optimismo y fe en la condición humana. Llegar a los 90 le hubiera dado la oportunidad de escribir, quizás, el último de la serie. La muerte no estuvo de acuerdo. Unos meses antes, la Asociación Psiquiátrica Peruana le había organizado un homenaje de reconocimiento por su $88^{\circ}$ cumpleaños. Parte del programa consistiría en la proyección de secuenciales diapositivas que expresaban en imágenes diversos aspectos de su trayectoria profesional. Sergio Zapata, uno de sus más distinguidos discípulos, había coleccionado una gama amplia de ellas. Entusiasmado el profesor por el evento, una semana antes, escogió con nosotros las mejores vistas a ser mostradas. Su cansado corazón no permitió que el homenaje se realizara en su presencia. Fue internado de urgencia en una clínica dos días antes, falleciendo en la mañana posterior a la fecha elegida y sin haber podido escribir la poesía de los $90^{\prime \prime}$ (6).

Me place ahora corregirme. Su hija Cristina, antes de volver a Europa luego de la muerte de su padre, me encargó disponer de los últimos libros de su biblioteca y donarlos

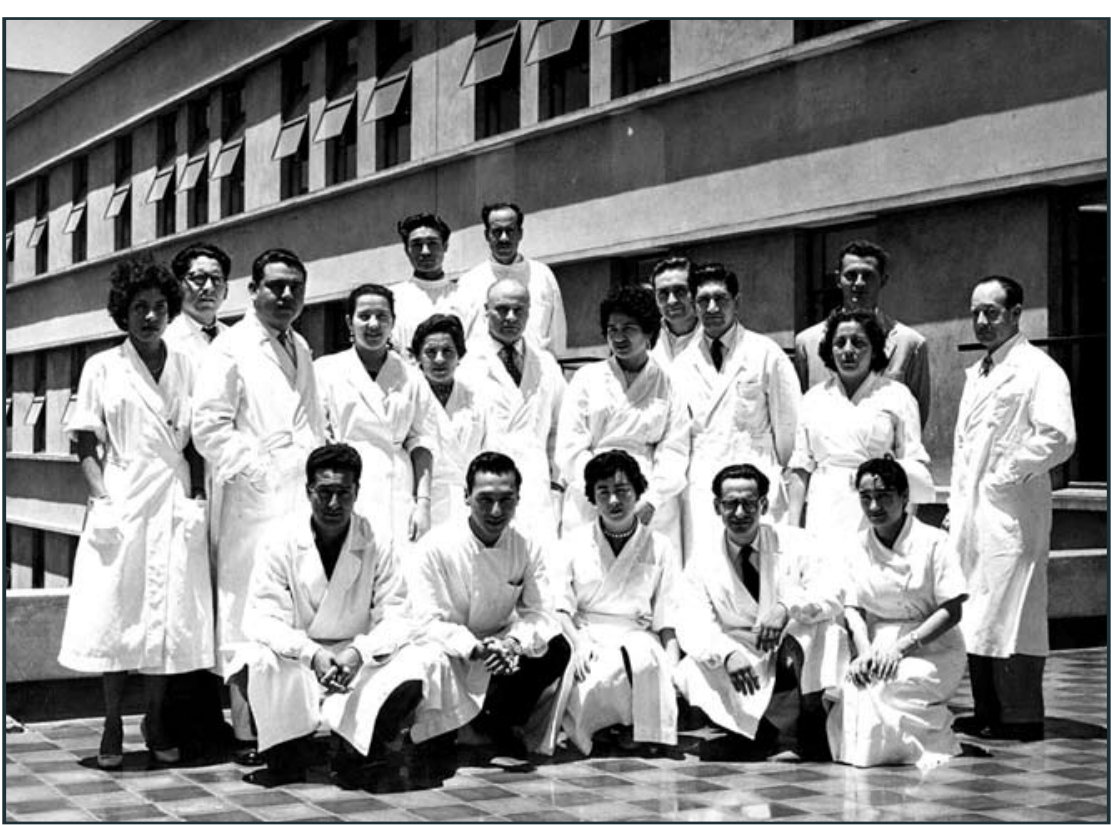

Figura 2. Miembros del personal del servicio de Psiquiatría del Hospital Obrero de Lima (actualmente Hospital Guillermo Almenara), 1957. Primera fila (en cuclillas) de izquierda a derecha: Dr. Carlos Crisanto, Dr. Alberto Perales, A.S. Beatriz Cuentas, Dr. José Alva, Enf. Olga Carrillo; segunda fila: Srta. Leonor Maturana (secretaria), Dr. M. Gutierrez (Honduras), T.O. Victoria Farromeque, Srta. Elena Lastra (secretaria), Dr. Carlos Alberto Seguín, Srta. Yolanda Alvarez (secretaria), Psic. Mauro Beas, Srta. Aida (secretaria), Dr. C. Gamarra;

tercera fila: Dr. Andrés Cáceres, Dr. Luis Vacaflor (Argentina), Dr. Enrique Documet; cuarta fila: Sr. Quintin (auxiliar), Enf. J. Tantaleán.

No estuvieron presentes: Drs. Oscar Valdivia, Sergio Zapata, Héctor Warnes, Enfs. Alicia Iglesias, Irene Yndiveri y Fridda Vargas (secretaria)

a nuestra Facultad de Medicina, tarea que cumplí. Serendipicamente, sin embargo, encontré entre ellos, un papel que por curiosidad revisé. Se trataba del borrador del poema, sobre su visión de la vida a los 90, que el Maestro, anticipándose, había redactado en su vieja máquina de escribir, de cinta azul, y cuyos caracteres todos sus discípulos reconocíamos al instante:

\section{"Versos de los noventa}

Voy a cumplir noventa largos años de choque continuado con el mundo; llenos de ilusiones y de desengaños y en búsqueda tenaz de lo profundo

Ha sido lucha larga y persistente

Que puede haberme conducido a un punto que me permitiera positivamente hallar la solución a un arduo asunto.

Se trata de lo noble y verdadero que, en su belleza, es grande y duradero $y$ alejado de todo fanatismo y que me ha permitido finalmente algo que quiero sea permanente: he logrado la paz conmigo mismo"

(Nota: copia textual del original, sin fecha)

\section{PALABRAS FINALES}

Dejo al lector las interpretaciones del caso, pero me permito destacar un hecho que puede ser cotejado con otras situaciones humanas límites, en la perspectiva Jasperiana, ante la muerte ${ }^{(7)}$. Seguín, como póstuma lección, nos enseña que para morir con dignidad, el hombre debe hacerlo 'en paz consigo mismo'.

Carlos Alberto Seguín permanecerá, por siempre, como uno de los grandes representantes de la medicina y psiquiatría peruanas y como paradigma docente de la Facultad de Medicina de San Fernando, de la Universidad Nacional Mayor de San Marcos.

\section{REFERENCIAS BIBLIOGRÁFICAS}

1. Silva M. Conversaciones con Seguin. Lima: Mosca Azul Editores; 1997.

2. Gracia D. Profesión médica, investigación y justicia sanitaria. En: Ética y Vida. Estudios de bioética 4. Bogotá: El Buho; 1994.

3. Alva J. Carlos Alberto Seguín en la docencia, en la investigación y el arte. Lima: Asociación Psiquiátrica Peruana; 2006.

4. Peña S. Aspectos de su vida y obra: Seguin y la psicoterapia. Lima: Asociación Psiquiátrica Peruana; 2006.

5. Cáceres A. Seguín y la medicina psicosomática. Lima: Asociación Psiquiátrica Peruana; 2006.

6. Perales A. Morir con dignidad: aspectos psiquiátricos. Boletín de la Academia Nacional de Medicina. 1999;1:6-7.

7. Jaspers K. Psicopatología General. Buenos Aires: Editorial Beta; 1955.

Manuscrito recibido el 10 de enero de 2008 y aceptado para publicación el 15 de febrero de 2008.

Correspondencia:

Alberto Perales Cabrera

Av. Javier Prado Oeste, 445. Of. 101

Lima 27, Perú

Correo-e: perales.alberto@speedy.com.pe 